RUNNING HEAD: TEACHER COLLABORATION

Transforming School Culture: Can True Collaboration Be Initiated?

Shui-fong Lam, Pui-shan Yim, \& Tom Wing-hong Lam

The University of Hong Kong

Correspondence should be addressed to Shui-fong Lam, Department of Psychology, The University of Hong Kong, Pokfulam, Hong Kong, China. E-mail:

lamsf@hkusub.hku.hk. Tel: 852-2859-2388. Fax: 852-2858-3518.

This research project was funded by the Committee on Research and Conference Grants at the University of Hong Kong and the Quality Education Fund of the Hong Kong Government. We are grateful to Mr. C. T. Chan, Ms. Y. S. Cheung, Mr. S. T. Chiu, Mr. K. K. Choi, Ms. Y. Y. Fung, Ms. E. Lau, Ms. P. W. Leung, Dr. A. Ma, Mr. P. W. Tam, Dr. E. Tsang, Mr. M. A. Wong, and Mr. C. H. Wu for their advice and assistance in the project.

Keywords: Teacher Development, Peer Coaching, Collaboration, School Culture 


\title{
Transforming School Culture: Can True Collaboration Be Initiated?
}

\begin{abstract}
While Western educators caution against contrived collegiality in the midst of enthusiasm for peer coaching as a form of teacher development, Hong Kong educators are struggling to detach discussion and observation of classroom teaching from staff appraisal. The challenges for this task are twofold: To secure a niche for peer coaching in the practice of staff development, and to ward off contrived collegiality in the course. Using an action research paradigm, the present project attempted to meet these challenges in two schools. As a joint work between various parties, the present project had to negotiate its way cautiously to achieve genuine collaboration and avoid imposition from the administrators and outsiders to the frontline teachers. During the course, innovative strategies were taken to cope with various difficulties including time constraints, teachers’ psychological pressure, and the possibility of contrived collegiality and implementation partnership. The evaluation of the project showed that the teachers generally accepted peer coaching and found it helpful to their professional development. The experience in the two schools indicated that true collaboration might emerge from organisationally induced collegiality under certain conditions.
\end{abstract}

Keywords: Teacher Development, Peer Coaching, Collaboration, School Culture 


\section{Transforming School Culture: Can True Collaboration Be Initiated?}

Peer coaching is a process of teachers helping teachers to reflect on present practices, learn new skills, and solve classroom-related problems through mutual goal-setting, classroom observation, and feedback sessions (Dalton \& Moir, 1991; Galbraith \& Anstrom, 1995). As a form of teacher development, peer coaching is caught in an embarrassing corner. On the one hand, peer coaching is widely recognised as an effective tool for teacher development. On the other hand, it is received by teachers with lukewarm support or even out-right resistance.

In an era of knowledge explosion, we acknowledge that teachers must keep up with the ever-changing society with continuous learning and adaptation. The relation between staff development and school improvement has been the subject of considerable literature over the past decade and a half (Wallace, 1998). In spite of its importance, staff development for teachers is usually a one-shot deal in the form of course or workshop without on-site continual coaching. As a result, what teachers learn from staff development courses does not necessarily transfer to actual practice in the classroom. In recent years, a number of educators and researchers have advocated methods of teacher development that are based on continuous collegial interaction and support (Gottesman \& Jennings, 1994; Hargreaves, 1988; Joyce \& Showers, 1983;

Little, 1982; Nias, Southworth, \& Yeomans, 1989; Shachar \& Shmuelevitz, 1997; Shimahara, 1998; Singh \& Shifflette, 1996; Smylie, 1988; Sparks, 1988; Spodek, 1996). Little (1982) finds that four practices characterise successful and adaptable schools. These four practices are: specific support for discussion of classroom practice, mutual observation and critique, shared efforts to design and prepare curriculum, and shared participation in the business of instructional improvement. Joyce and Showers 
(1983) also find that peer observation or coaching have tremendous impact on the transfer of knowledge and skills from staff development course to classroom practice. Their findings have been repeatedly replicated by many other researchers (Sparks, 1988; Singh \& Shifflette, 1996).

In spite of the strong evidence that peer coaching or sharing is a promising way for teacher development, teachers generally do not welcome it. Little (1985) argues that the interactions that focus on actual classroom performance are potentially most useful yet most demanding because they expose how teachers teach to the scrutiny of peers. These interactions place teachers' self-esteem and professional respect on the line. As Gottesman and Jennings (1994) have noted, classrooms are usually very isolated places and there is subtle resistance from teachers against having another adult in their classroom. In a survey of Hong Kong educators, Lam (2001) found that a considerable percentage of Hong Kong teachers did not welcome their peers to their classroom.

The resistance to peer sharing and observation makes an awkward and ironic contrast to the recognition that peer sharing and observation is an effective form of teacher development. Causes for the resistance are numerous. Among them, the culture of classroom isolation is the most often cited. Lortie (1975) describes classroom isolation as one of the most pervasive characteristics of teaching. In such a culture, teachers are separated into classes, isolated and insulated from one another's work. The isolation may protect teachers from inspection and intrusion but it deprives teachers of the opportunities to learn from and with one another, and to reflect on crucial aspects of teaching. Hargreaves (1988) succinctly states that "team-teaching, exploration of new methods, collaborative approaches to improve teaching, 
constructive collegial criticism of classroom performance - none of these things are fostered by the isolation and individualism of the existing culture of teaching” (p.226).

The resistance that results from the culture of isolation is detrimental to teacher development and school improvement. However, the resistance that results from the boycott on "contrived collegiality” may be adaptive. According to Hargreaves' mircro-political critique of collegiality (1994), contrived collegiality is an administratively imposed and controlled form of collegiality. He distinguishes contrived collegiality from collaborative cultures that are sustained by the teachers themselves spontaneously. He states that contrived collegiality is administratively regulated, compulsory, implementation-oriented, fixed in time and place, and predictable. In contrast, collaborative cultures are spontaneous, voluntary, development-oriented, pervasive in time and space, and unpredictable. He argues that under the conditions of contrived collegiality, teachers are required to work together to implement the mandates of others. Instead of being empowered, teachers feel coerced to conform. This is particularly true for the peer coaching of the technical kind that is uncritical of the rationale for the implementation of the skills being coached. In a critique of technical peer coaching, Hargreaves and Dawe (1990) poignantly point out that many teachers strategically distance themselves from the peer coaching that is contrived, inauthentic, and mandated by administrators.

In Hong Kong, teachers’ resistance to peer sharing or coaching may have a different set of causes. Peer sharing or coaching, whether contrived or not, is rarely practised in Hong Kong. Teacher isolation is the norm. In Lam’s survey (2001), half of the respondents indicated that they never practised classroom observation in their schools. For the rest who indicated that they had such practice, the observation was mostly not peer sharing or coaching. It was mainly an appraisal activity done by the 
supervisors to the subordinates. However, when asked what would be their ideal objective and format of classroom observation, the respondents clearly indicated that they wanted peer observation that primarily aimed at staff development. The voices of Hong Kong teachers are loud and clear: they would like to make a change.

Literature in the West, produced in the past decade and a half has no shortage of advocacy for collaboration, peer coaching, collegiality, partnership, and similar approaches. In the face of the plethora of these compelling images, many authors caution against the optimism attached to collaboration. Little (1990) confronts the specified forms of induced collaboration and queries their effectiveness if they are not congruent to the naturally occurring relations among teachers. Hargreaves and Dawes (1990) criticise contrived collegiality for its flavour of "supervisory evangelism” under the aegis of professional collaboration and personal development. To change the culture of isolation, the challenge for Western educators is to keep their collaboration free from the contrived collegiality, an imposition which is not conducive to their genuine joint work on reflection about the purpose, value, and consequences of what they teach. In Hong Kong, our challenge is more than that.

In Hong Kong, peer collaboration for staff development is rarely practised. If classroom teaching is observed or discussed, it is mostly for the sake of staff appraisal. This background does not mean that we need not attend to the threat of contrived collegiality when we press for the methods of teacher development that are based on continuous collegial interaction and support. Nevertheless, before we put in this caveat, we have to fight for the place of peer collaboration in the existing culture. Hong Kong educators face two challenges. The first is to detach the discussion and observation of classroom teaching from staff appraisal and secure a niche for it in the practice of staff development. The second is to ward off contrived collegiality in the 
development of peer collaboration. The present project was an attempt to meet these challenges.

\section{Methods}

\section{$\underline{\text { Action Research }}$}

Using the paradigm of action research, the present project was a collaboration between university researchers and front-line teachers. The project was initiated by a research group in the University of Hong Kong and the leaders in the Education Convergence. The Education Convergence is an active educational body formed by a group of front-line educators in Hong Kong. In response to a note of invitation in the newsletter of the Education Convergence, four schools volunteered to participate in the project. Eventually two schools were selected. One was a primary school with 560 students and 38 teachers; the other, a secondary school with 900 students and 50 teachers. Both were Government subsidised schools with students primarily of lowermiddle class background from the public housing estates in their neighbourhood.

Before these two schools were chosen for the study, the researchers from the university and the representatives of the Educational Convergence visited all four schools that had indicated interest. In each of these meetings, the principal and the middle management of the school were present. Different parties expressed their understanding and expectations of peer coaching. Eventually the two schools aforementioned were selected because of their readiness for peer coaching and their compatibility of beliefs and values with the other parties of the project. All the parties agreed to define peer coaching as an interaction in which teachers talk about and reflect on their classroom teaching, design and plan teaching materials together, are 
observed by and learn from one another. This activity is detached from staff appraisal and does not only focus on the coaching of technical skills.

In the summer before the project was launched, an action research team was formed in each of the two schools. It consisted of a core group of teachers, the researchers from the university, and the representatives of the Education Convergence. The core group in each school was composed of the principal and six to seven teachers who volunteered to participate.

\section{The Process of the Project}

The project was divided into three phases: 1) Preparation phase (June 1998 to August 1998), 2) Implementation phase (September 1998 to July 1999), and 3) Evaluation phase (August 1999 to December 1999). The action plans in the project were made, implemented, and evaluated by the concerted effort of the members of the action research teams. Meetings were held regularly among the teachers of the schools, the researchers from the university, and the representatives of the Education Convergence to monitor and evaluate the project.

To ensure that the action plans reflected the understanding, opinions, and willingness of all the other teachers and that the project was not dictated by the action research team in each school, three school-based staff development workshops which involved all the teachers were held. The researchers from the university facilitated these workshops and helped forging the consensus among the teachers. In the first workshop that was held before the school year, the teachers reviewed the objectives of classroom observation in their school and expressed what they wished for the activity in the coming year. In the middle of the school year, a second workshop was held. It provided an opportunity for all the teachers to discuss their preferred format of peer 
coaching and delineated the “dos” and “don'ts” in the process. In the last workshop at the end of the school year, the teachers shared their experiences and evaluated what they had gone through in the year. These school-based staff development workshops were forums in which all the teachers openly discussed the direction and processes of the action plans. Consensus among all the teachers were reached before the action plans were implemented.

\section{$\underline{\text { Data Collection Methods }}$}

Research data were collected through regular meetings, staff development workshops, semi-structured interviews, questionnaire surveys, and observation.

Meetings among the core group of the school, the researchers from the university, and the representatives of the Education Convergence were held every two or three months to monitor the progress of the project. Comments and feedback from various parties were collected during these meetings. The aforementioned staff development workshops also provided opportunities for the action research team in each school to collect opinions from the teachers. Semi-structured interviews were conducted with randomly selected teachers at the end of each semester. The interviewers were the researchers from the university. They compiled the data and presented them to the action research teams in the regular meetings.

At the beginning and the end of the school year, all teachers were invited to complete an anonymous questionnaire. In the questionnaire survey at the beginning of the school year, the teachers were requested to indicate their expectations and perceptions of the classroom observation activity in their schools. They were asked to indicate its ideal purpose and format according to their preferences. They were also asked to indicate its actual purpose and format according to their observation. They 
were asked to rate the statements such as "classroom observation in our school is primarily for staff appraisal” twice on a 7-point scale with “1” for "strongly disagree” and "7” for "strongly agree.” The first rating was according to their preferences and the second their actual observation.

At the end of the school year, the teachers were requested to rate the statements again in a questionnaire survey. This time they were asked to indicate the extent to which they agreed that these statements accurately described the actual practice of their schools in that year. In the same questionnaire survey, they were also asked to evaluate the present project and how much they would like to support peer coaching. They were asked to indicate the extent to which they agreed to the statements such as "the objective of peer coaching in my school this year is consistent with my own objective for it.” The rating was on a 7-point scale with “1” for “strongly disagree” and "7” for “strongly agree."

Results

\section{Model of Peer Coaching}

After thorough discussion in the action research team meetings and the first two staff development workshops, the two schools adopted a format of research lesson that is popular in Japan (Lewis \& Tsuchida, 1998). The activity of a research lesson is separated from staff appraisal and its sole purpose is staff development. The direction of a research lesson is deviated from the usual practice in Hong Kong where classroom observation has a strong flavour of staff appraisal. However, it is in line with the demands of the teachers in the two schools as indicated by them in their first staff development workshop and the questionnaire survey at the beginning of the 
school year. As shown in the column "Ideal Situation before the Project" in Table 1, teachers from both schools indicated that they wished that classroom observation in their schools would be primarily for staff development rather than appraisal. They also wished that it would be an activity in which teachers observing one another rather than principal observing teachers.

\section{Insert Table 1 about here}

A typical research lesson in the two schools composed of three sessions: 1) Preparation meeting, 2) Classroom observation, and 3) Discussion. Each session was attended by a group of teachers, usually four to five teaching the same subject. In the preparation meeting, the teachers would discuss how to teach a certain unit of the curriculum. All would contribute to the development of the lesson plan. In the classroom observation, the lesson plan would be tried out by one teacher and observed by the others. In the discussion session, the observed and the observers would come together for a review. In the present project, experienced teachers from other schools or lecturers from teachers college would be present in most of the sessions for consultation. These advisory teachers, mostly the members of the Education Convergence, were invited through the network of the Convergence.

During the school year, 28 research lessons took place in the primary school and 17 in the secondary school. Almost every primary school teacher participated at least once in these 28 research lessons. About $80 \%$ of the secondary school teachers participated at least once in the 17 research lessons in their school. The research lessons in the primary school spread evenly throughout the school year whereas those in the secondary school concentrated in the second semester. 


\section{$\underline{\text { Difficulties and Coping Strategies }}$}

In both workshops and questionnaire survey, the teachers reported that time constraints and psychological pressure were the two most outstanding difficulties for their participation in peer coaching.

Time constraints. The excessive workload of Hong Kong teachers is well documented (Board of Education, 1997; Lam, Yuon, \& Mak, 1998). Teachers in Hong Kong are involved in a lot of administrative/clerical work that is not related to teaching. To make the situation worse, the Hong Kong Government has recently launched many educational innovations (Education Commission, 2000). Being overwhelmed by all these new changes, the teachers in the two participating schools found it difficult to squeeze time out from their tight schedules for peer coaching. Further, the format of research lesson adopted in the present project made the time tabling more difficult. The research lesson required three or four teachers teaching the same subject to develop a lesson together and review the process after the lesson. It was difficult to schedule a meeting that could fit the timetable of three or four teachers.

To solve the problem of time constraints, the action research teams in both schools tried to start the peer coaching activity small and slow according to the acceptance and pace of the teachers. The primary school focused on four subjects and did not involve all the teachers in the first semester. The secondary school did not start the peer coaching activity until the second semester. In the first semester, the secondary school was under the Quality Assurance Inspection ${ }^{1}$. A team of inspectors

\footnotetext{
${ }^{1}$ Since 1997 the Education Department in Hong Kong has adopted a whole-school approach to replace the subject-based approach in school inspection. The Education Department conducts inspection to schools selected on random basis to provide an external review and to make open inspection findings. The Education Department aims to achieve the due balance between providing support to schools through school improvement and exerting pressure through accountability.
} 
from the Education Department visited the school many times during this period.

Most of the teachers in the secondary school were exhausted and could not entertain any other educational innovation. In view of this difficulty, the action research team in that school decided to postpone the activity until the second semester and conduct less research lessons.

To ameliorate the problem of time constraints, each school hired a full time substitute teacher to take up some of the classes and administrative work of the other teachers. The expense for such a position was covered by the funding agencies for the present project.

Psychological pressure. $\quad$ The teachers in the two participating schools stated that psychological pressure was another major concern. This message was clear and consistent across the group discussion in the staff development workshops, structured interviews, and questionnaire surveys. The teachers felt that their selfesteem and professional respect were on the line. They were afraid that their colleagues might form negative judgements about their performance and ability if anything went wrong, e.g., the students were not co-operative.

To relieve the teachers from psychological pressure, the action research team in each school tried many strategies. The most effective one was to detach peer coaching from staff appraisal. As pointed out by Lam (2001), peer coaching that is independent of appraisal will allow teachers to make the best use of this collegial support without the apprehension of performance review. The teachers in the two schools also expressed similar opinions (see Table 1). The action research team in each school, therefore, took many measures to ensure the teachers that peer coaching had nothing to do with staff appraisal. The principals of both schools did not take part 
TEACHER COLLABORATION

in the classroom observation lest the teachers felt that they were under supervision by their super-ordinates. To break the ice, the experienced teachers in the middlemanagement of both schools also volunteered to be observed first. In the secondary school, the action research team delegated the co-ordination work of peer coaching to the Staff Development Committee that organised staff development activities in the school. Previously, the practice of classroom observation in that school was coordinated by the Academic Affairs Committee that was responsible for job assignments and monitoring. The transfer from the Academic Affairs Committee to the Staff Development Committee symbolised the determination of the school in decoupling peer coaching from staff appraisal. In both schools, no record or document of peer coaching would be placed in the personnel files of the teachers. This measure further assured the teachers that the activity had nothing to do with staff appraisal.

To discontinue the use of rating scale in classroom observation was another major measure to relieve the teachers from psychological pressure. The use of rating scale in classroom observation is widespread in Hong Kong. Both participating schools had been using some sort of rating scale in classroom observation before the present project was launched. The use of rating scale in peer coaching was under debate in the second staff development workshop in both schools. Some teachers queried the use of rating scale because it had strong flavour of evaluation. However, some other teachers argued that rating scale provided clear, objective, and convenient guidelines for the observation.

There was an interesting debate among the teachers in one of the staff development workshops. At the end, they came to a consensus that rating scale might not be helpful in peer coaching that did not care about staff appraisal. They agreed that the content of observation should not be dictated by the items on a standardised 
rating scale. It should be the common concerns of the observers and the observed, e.g., How to use co-operative learning method with a group of $4^{\text {th }}$ graders in Art and Craft lesson? How to ensure their on-task time when they are left to group discussion by themselves? How to instil individual accountability to group assignment? All these questions are focused on how to help the students learn better instead of how well the teacher performs his or her task. In other words, the focus is the students instead of the teacher. On the basis of this argument, most teachers agreed that rating scale that focused on the evaluation of the teacher's performance did not help much in peer coaching. They agreed that the content of the observation should be discussed and agreed by the observers and the observed in the preparation meeting before the observation. At the end of the school year, many teachers expressed that their psychological pressure was ameliorated when they knew that their performance was not on the line.

Although the format of research lesson had made time tabling more difficult, it relieved teachers from psychological pressure. At the end of the school year, many teachers independently stated that they preferred the format of research lesson because of its implication on collective responsibility and shared ownership. They pointed out that in a research lesson, the lesson was developed with joint effort of the observed and the observers. Therefore, every one was responsible for addressing the concerns raised in the preparation meeting. When the responsibility and ownership were shared, the teachers being observed felt less pressure. Instead, they felt that they were supported by a group of partners in the search for solutions to pedagogic problems. The researchers from the university also observed the existence of such a collective responsibility among the teachers. During a discussion after classroom observation, a researcher from the university raised a question about an activity in the 
TEACHER COLLABORATION

lesson. The one who responded to the question was not the teacher being observed but one of the teachers who observed the lesson. He helped to develop this lesson plan and thus assumed the responsibility to make clarification about it.

The aforementioned strategies that helped ameliorate teachers’ psychological pressure were tangible arrangements or re-arrangements in doing things. However, the most helpful factor that was often cited by the teachers was something intangible in their schools: the trustful relationship among themselves. During the last staff development workshop, some teachers explicitly stated that the climate of collegiality helped them tackle psychological pressure the most. Mutual trust and assistance among colleagues could even alleviate the pressure brought by time constraints and heavy workload.

Contrived collegiality and implementation partnership. $\quad$ In his critique of contrived collegiality, Hargreaves (1991) argues that while teacher collegiality mechanisms may appear teacher-driven and reflective of genuine teacher collaboration, they may also promote administrative convenience and result in teachers being coerced to conform. Hargreave’s micro-political analysis in collegiality is echoed by Biott's (1992) thesis on imposed support for teachers. Biott poignantly points out that teachers will not appreciate support from advisory teachers when the partnership is characterised by an emphasis on the implementation of a task or plan initiated by the advisory teachers. To correct this, Biott advocates giving up “implementation partnership” for “development partnership” in which teachers and advisory teachers work out solutions together. When the university researchers initiated the present project, they were apprehensive of the threat of contrived 
collegiality and implementation partnership. During the course, such threat appeared from time to time.

Before the project was launched, the researchers from the university, the representatives of the Education Convergence, and the school personnel all understood that the project was an action research that required all the parties to seek and try out solutions together. However, some teachers still expected leadership and advice from the external experts. In one of the staff development workshops, a group of teachers suggested that the peer coaching project would be more efficient if they could be informed of the format, scope, timing, and other administrative arrangements at the very beginning of the school year. Some external advisory teachers also noticed that many teachers looked up to them for authoritative comments and suggestions in the discussion and observation of classroom teaching. One external advisory teacher succinctly described the mismatch between his and the teachers' expectations: “The teachers expect me to lead their discussion and provide them with authoritative suggestions. However, I don't expect myself as a leader who provides top-down leadership. I hope that I can facilitate their independent search for solutions.”

The researchers from the university and the external consultants were stuck in an embarrassing dilemma. The invitation to provide leadership and authoritative suggestions was tempting and compelling. However, once they accepted such an invitation, they would soon find that the suggestions that were not developed by the teachers could not cater to the teachers' needs. Their advice and suggestions would become the nuisances in contrived collegiality and implementation partnership. In our present project, a group of teachers complained that the advisory teacher who sat in their discussion was not helpful because his suggestions were "abstract,” “theoretical,” and “irrelevant.” However, when the researchers from the university 
and the external consultants declined the invitation to provide leadership and authoritative suggestions, they were also criticised for not being helpful.

To get out of the dilemma, all the partners in the action research project had to meet regularly to ensure open communication among all parties. Although the action research team co-ordinated the action plans, it strove to obtain consensus among all the other teachers for the development and implementation of these plans. As a result, the process was slow and inefficient because quick decision could not be made centrally. This explained why some teachers felt that they were not informed of the format, scope, timing, and the other administrative arrangements at the very beginning of the school year. Actually the members of the action research team deliberately did not inform the teachers of these action plans but to invite them to discuss and develop the solutions that best fit their needs. We were willing to sacrifice administrative efficiency for the slow formation of shared beliefs, values, and norm among the teachers. The secondary school did nothing on peer coaching activity in the first semester because of the unexpected Quality Assurance Inspection. There was subtle pressure to hold the project accountable for its funding agencies but the action research team in the secondary school still let the teachers decide when to start the activity.

Most external advisory teachers in this project were aware of the negative consequences of implementation partnership. Before they participated in the peer coaching activities in the two schools, they met with the action research team members and discussed their roles and functions. Most of them agreed to adopt the strategies of "asking," “inquiring," “discussing,” and “developing” in development model and avoid the strategies of "giving," "telling," "showing,” and "implementing” in the implementation model (Biott, 1992). They saw themselves as the partners of the 
teachers in problem solving rather than the experts who already knew what plans would be best and told the teachers how to implement these plans. As a result, their approach was welcome by the teachers who applauded the "development partnership” but queried by the teachers who expected more direct guidance from them.

\section{$\underline{\text { Program Evaluation }}$}

The teachers of the two schools were requested to complete questionnaires at the beginning and the end of the school year. By comparing the results of these two questionnaires, we found that the teachers maintained a positive perception of the project despite the aforementioned difficulties. In most aspects, the classroom observation practised in their schools in that year was close to their expectations and better than the actual situation they stated at the beginning of the school year (see Table 1). At the beginning of the school year, the teachers indicated that they hoped that the classroom observation in their schools would be less for staff appraisal and more for staff development. They also hoped that the principal would observe teachers less while teachers would observe one another more. At the end of the school year, the teachers' ratings indicated that the classroom observation in their schools was less for staff appraisal than a year ago. Further, the principal observed teachers less while teachers observed one another more than they reported a year ago. However, the teachers did not report that the classroom observation in their schools was more for staff development than a year ago. This might due to the relatively high baseline for this item at the beginning of the school year. The teachers did not change much of their ratings after the project. Both before and after the project, the teachers agreed that the classroom observation in their schools was for staff development. 
In the questionnaire survey at the end of the school year, the teachers were also requested to respond to a group of questions that tapped their evaluation and support for the peer coaching project. The results are presented in Table 2. In general, the teachers tended to agree that the project had effectively enhanced their teaching quality, mutual communication, and understanding. They also tended to agree that the objective and format of the peer coaching that took place in their schools were congruent with their expectations. When asked if they were willing to participate in peer coaching despite the time constraints and difficulty in scheduling, their answers tended to be positive. When asked whether they were still willing to support their schools in the development of peer coaching after they had considered the time they had spent and the psychological pressure they had felt, their answers also tended to be positive. When asked if they would not participate in similar peer coaching project if they could choose again, they tended to indicate that they would do it again. In general, the teachers from both schools had positive evaluation of the project and showed acceptance and support to peer coaching despite the difficulties.

Insert Table 2 about here

\section{Discussion}

In the present project, we initiated peer coaching in two schools. Although we encountered many difficulties during the course, our experience was mostly positive. We believe that the insistence on an action research paradigm and the emphasis on collaboration in the process helped us to cope with the difficulties. Although the practice of peer coaching was initiated by the school administrators and some external 
supporters, it was not imposed on the teachers. It evolved slowly through continuous consultation and collaboration among various parties. Grimmett and Crehan (1992) argue that any attempt at initiating collegiality is inevitably contrived. However, they also make a clear distinction between the administratively imposed type of contrived collegiality and the organisationally induced type of contrived collegiality. The former is undesirable but the latter has a chance to evolve into genuine collaborative culture. According to them, administratively imposed collegiality consists of 'topdown' attempts to manipulate directly the collaborative practices or behaviours of teachers. In other words, the emphasis is placed on fulfilling the form of collegiality without regard for the underlying assumptions of collaboration. Teachers were mandated to collaborate voluntarily. This paradox betrays an absurd contradiction to the spirit of genuine collaboration. In contrast, the organisationally induced collegiality, as described by Grimmett and Crehan (1992), is “characterised by 'topdown' attempts at fostering 'bottom-up’ problem-solving approaches to school improvement through careful manipulation, not of teachers’ practices and behaviours, but of the environment within which teachers live and work and have their professional being” (p. 70) .

When we initiated the practice of peer coaching in the two schools, we tried our best to avoid the administratively imposed type of contrived collegiality. We also tried our best to manipulate the environment so that the teachers could make use of the practice for their professional needs. It is never easy to avoid the administratively imposed collegiality because the demands for administrative efficiency and fulfilment of the requirements of innovation under experiment are usually very strong. It will be too slow and too inefficient to gain consensus and ensure collaboration from teachers for each step of the process. The difficulty is aggravated by a propensity of school 
personnel to rely on suggestions and advice from external experts. Our reaction to these difficulties was to insist on the action research paradigm and the emphasis on genuine collaboration in the process. This might result in administrative inefficiency and teachers' disappointment. However, we believe that it was worthwhile.

We also tried various strategies to manipulate the environment so that peer coaching became natural to the teachers. These strategies included the adoption of research lesson format; small scale of the activity at the beginning; slow process according to the acceptance and pace of the teachers; hiring substitute teachers to reduce teachers' workload, and a series of measures that ensured de-coupling of peer coaching activity from staff appraisal.

The strategies that detach peer coaching from staff appraisal can ameliorate teachers’ psychological pressure because they help teachers to re-orient themselves from performance goal to learning goal. Dweck and her associates (Dweck, 1986; Dweck \& Leggett, 1988; Cain \& Dweck, 1995) posit that people may have different goal orientations in learning. Some people may adopt a performance goal, aiming at gaining positive judgements and avoiding negative judgements of their competence. Some people may adopt a learning goal, aiming at increasing their competence instead of documenting their competence. Learning can be a risk-taking activity in which one’s competence may be subject to judgements. To open up one’s classroom teaching for observation and discussion can facilitate learning but it can also incite psychological pressure. The psychological pressure would be most intense for the teachers who espouse performance goal. When the flavour of appraisal is strong in the peer coaching activity, the teachers will be prone to performance goal instead of learning goal because it is natural for one to seek positive judgements of one’s performance during appraisal. When peer coaching is detached from staff appraisal, 
teachers are more able to give up performance goal and endorse learning goal. With the change of this culture, teachers’ psychological pressure will be ameliorated and their acceptance of peer coaching will be natural and genuine.

The two participating schools had taken innovative strategies to ensure the decoupling of peer coaching and staff appraisal. These measures included the principals' appropriate withdrawal from the coaching activity, the delegation of co-ordination work to the Staff Development Committee, the discontinuation of the use of rating scale, and the cultivation of collective responsibility in research lesson. All these measures manipulated the teachers' environment instead of their practices and behaviours directly. They only affected the teachers’ practices and behaviours indirectly by clearing the possible hindrances and cultivating an amicable culture.

Without the right culture, the practice of peer coaching will not generate genuine collaboration. As pointed out by Little (1991), attempts at initiating collaboration will only produce the artefacts if no effort has been made to nurture the underlying beliefs, values, and norms that make up the sustaining culture. Our experience in the two schools corroborated the claim of Little. At the end of the school year, many teachers explicitly stated that what relieved them most from their psychological pressure was the trustful relationship among themselves. This intangible culture was indispensable to the present project.

The attempts at initiating collaboration will be successful when there is a school culture congruent with collaboration. Then will this phenomenon be a paradox of egg and chicken? One has to start somewhere. We do not think that we should not initiate collaboration when there is little collaborative culture in the school. The pivot lies in the deliberate attempts on the part of initiators. These attempts should influence indirectly teachers’ professional practices and behaviours by careful 
manipulation of the environment in which the school culture develops. If the emphasis is placed on the fulfilment of the format of collegiality without the regard for the development of the culture, any attempt to initiate collaboration will only result in administratively imposed collegiality whose effects will be subverted. School culture consists of the beliefs, values, and norms which govern what is of worth to the school and how the members should think, feel, and behave (Sergiovanni, 1984). The formation of collaborative school culture is a slow process that requires the input of every member of the school. It defies the administrative procedures that only value administrative efficiency and the fulfilment of format requirements. 


\section{References}

Biott, C. (1992). Imposed support for teachers’ learning: implementation or developmental partnership. In C. Biott \& J. Nias (Eds.), Working and learning together for change (pp. 3-18). Philadelphia: Open University.

Board of Education. (1997). Report on review of 9-year compulsory education. Hong Kong: Government Printer.

Cain, K. M., \& Dweck, C. S. (1995). The relation between motivational patterns and achievement cognitions through the elementary school years. MerrillPalmer Quarterly, 41, 25-52.

Dalton, S., \& Moir, E. (1991). Evaluating LEP teacher training and in-service programs. Paper presented at the Second National Research Symposium on Limited English Proficient Student Issues. Washington, DC.

Dweck, C. S. (1986). Motivational processes affecting learning. American Psychologists, 41, 1040-1048.

Dweck, C. S., \& Legget, E. L. (1988). A social-cognitive approach to motivation and personality. Psychological Review, 95, 252-273.

Education Commission (2000). Review of Education System: Reform Proposals. Hong Kong: Government Printer.

Galbraith, P., \& Anstrom, K. (1995). Peer coaching: An effective staff development model for educators of lingustically and culturally diverse students. Directions in Language and Education, 1(3).

Gottesman, B. L., \& Jennings, J. O. (1994). Peer coaching for educators. Lancaster: Technomic. 
TEACHER COLLABORATION

Grimmett, P. P., \& Crehan, E. P. (1992). The nature of collegiality in teacher development: The case of clinical supervision. In M. Fullan, \& A. Hargreaves (Eds.), Teacher development and educational change (pp. 56-85). London: Falmer Press.

Hargreaves, A. (1988). Teaching quality: a sociological analysis. Journal of Curriculum Studies, 20(3), 211-231.

Hargreaves, A. (1991). Contrived collegiality: The micropolitics of teacher collaboration. In J. Blase (Ed.), The politics of life in schools: Power, conflict, and cooperation. (pp. 161-184). Newbury Park, CA: Sage Publications.

Hargreaves, A. (1994). Changing teachers, changing times: Teachers’ work and culture in the postmodern age. London: Cassell.

Hargreaves, A., \& Dawe, R. (1990). Paths of professional development: Contrived collegiality, collaborative culture, and the case of peer coaching. Teaching and Teacher Education, $\underline{6}(3), 227-241$.

Joyce, B., \& Showers, B. (1982). The coaching of teaching. Educational Leadership, $\underline{40}$ (1), 4-10.

Lam, S. F. (2001). Educators' opinions on classroom observation as a practice of staff development and appraisal. Teaching and Teacher Education, 17, 161-173.

Lam, S. F., Yuon, E., \& Mak, Y. S. (1998). Support services to secondary school teachers in Hong Kong. Education Journal, 26(1), 77-99.

Lewis, C., \& Tsuchida, I. (1998). A lesson is like a swiftly flowing river: How research lessons improve Japanese education. American Educator, 22(4), 12-17, 5052.

Little, J. W. (1981). The power of organization setting: School norms and staff development. Paper presented at the annual meeting of the American Educational Research Association, Los Angles, CA. 
Little, J. W. (1982). Norms of collegiality and experimentation: Workplace conditions of school success. American Educational Research Journal, 19(3), 325-340.

Little, J. W. (1985). Teachers as teacher advisors: the delicacy of collegial leadership. Educational Leadership, $\underline{43}$ (3), 34-36.

Little, J. W. (1990). The persistence of privacy: autonomy and initiative in teachers’ professional relations. Teachers College Record, 91(4), 509-536.

Lortie, D. (1975). School-teacher. Chicago: University of Chicago Press.

Nias, J., Southworth, G., \& Yeomans, R. (1989). Staff relationships in the primary school: A study of organizational cultures. London: Cassell.

Sergiovanni, T. J. (1984). Leadership and excellence in schooling. Educational Leadership, $\underline{42}$, 5, 4-13.

Shachar, H., \& Shmuelevitz, H. (1997). Implementing cooperative learning, teacher collaboration and teachers’ sense of efficacy in heterogeneous junior high schools. Contemporary Educational Psychology, 22, 53-72.

Shimahara, N. K. (1998). The Japanese model of professional development: Teaching as craft. Teaching and Teacher Education, 14, 451-462.

Singh, K., \& Shifflette, L. M. (1996). Teachers’ perspectives on professional development. Journal of Personnel Evaluation in Education, 10, 145-160.

Smylie, M. A. (1988). The enhancement function of staff development: Organization and psychological antecedents to individual teacher change. American

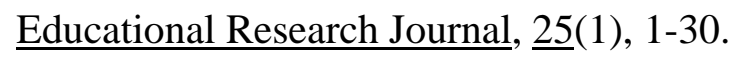

Sparks, G. M. (1986). The effectiveness of alternative training activities in changing teaching practices. American Educational Research Journal, 23(2), 217-225. Spodek, B. (1996). The professional development of early childhood teachers. Early Child Development Care, $\underline{115}, 115-124$. 
Wallace, J. (1998). Collegiality and teachers' work in the context of peer supervision. Elementary School Journal, 99(1), 81-98. 
Table 1

Teachers' Perception of Classroom Observation Activity Before and After the Project

\begin{tabular}{|c|c|c|c|}
\hline Statements & $\begin{array}{l}\text { Ideal } \\
\text { Situation } \\
\text { Before the } \\
\text { Project }\end{array}$ & $\begin{array}{l}\text { Actual } \\
\text { Situation } \\
\text { Before the } \\
\text { Project }\end{array}$ & $\begin{array}{l}\text { Actual } \\
\text { Situation } \\
\text { After the } \\
\text { Project }\end{array}$ \\
\hline & $(\mathrm{n}=74)$ & $(\mathrm{n}=50)$ & $(\mathrm{n}=68)$ \\
\hline $\begin{array}{l}\text { 1. Classroom observation in our school is } \\
\text { primarily for staff appraisal. }\end{array}$ & 3.93 & 4.81 & 3.70 \\
\hline $\begin{array}{l}\text { 2. Classroom observation in our school is } \\
\text { primarily for staff development. }\end{array}$ & 6.02 & 5.62 & 5.22 \\
\hline $\begin{array}{l}\text { 3. Principal observing teachers is the primary } \\
\text { format of classroom observation in our } \\
\text { school. }\end{array}$ & 3.21 & 3.68 & 2.42 \\
\hline $\begin{array}{l}\text { 4. Teachers observing one another is the } \\
\text { primary format of classroom observation in } \\
\text { our school. }\end{array}$ & 5.53 & 4.90 & 5.72 \\
\hline
\end{tabular}

Note. The respondents indicated their agreement to these statements on a 7-point scale, " 1 ” for "strongly disagree," "7" for "strongly agree," and " 4 ” was the midpoint that indicated neutral attitude. The new teachers in both schools were not required to respond to the items about the actual situation before the project. 
Table 2

Teachers' Evaluation of the Peer Coaching Project

Evaluation Item

Total

$(\mathrm{n}=68)$

1. The peer coaching project has effectively enhanced our

4.90 teaching quality.

2. The peer coaching project has enhanced the communication and understanding among us.

3. The objective of peer coaching in my school this year is congruent with my own objective for it.

4. The format of peer coaching in my school this year is congruent with my preferred format for it.

5. Despite the time constraints and difficulty in scheduling, I am willing to participate in peer coaching .

6. Considering the time I have spent and the psychological pressure I have felt, I am still willing to support my school in the development of peer coaching.

7. Given freedom to choose again, I shall not participate in similar peer coaching project.

Note. The respondents were required to indicate their agreement to these statements on a 7-point scale, “1” for “strongly disagree," “7” for "strongly agree,” and “4” was the midpoint that indicated neutral attitude. 